\title{
Prevalence of early childhood caries and associated risk factors in preschool children of urban Bangalore, India: A cross-sectional study
}

\author{
Prashanth Prakash ${ }^{1}$ \\ Priya Subramaniam² \\ B.H.Durgesh ${ }^{3}$ \\ Sapna Konde ${ }^{4}$
}

\section{ABSTRACT}

Objectives: Early childhood caries (ECC) is a devastating form of dental decay with multi-factorial origin. The aim of this cross-sectional study is to investigate the prevalence and related risk factors of ECC in preschool children of urban Bangalore (India).

Methods: A random sample of 1,500 children aged between 8 and 48 months were selected from various parts of urban Bangalore. The status of dental caries was recorded according to the World Health Organization (WHO) criteria. Information regarding oral hygiene practices, feeding habits, socio-economic status, birth weight, and educational status of the mother was obtained through a structured questionnaire given to mothers of preschool children. The data was subjected to statistical analysis using the Statistical package for social sciences (SPSS) version 12.

Results: The prevalence of ECC in preschool children was $27.5 \%$, while the mean deft was 0.854 . ECC increased significantly with age. Children whose mothers had no schooling and those who belonged to low socioeconomic group showed higher caries prevalence. A significant increase in caries prevalence was found in children accustomed to the practice of on-demand breast feeding and bottle feeding at night. Caries also increased significantly when snacks were consumed between meals. However, increased frequency of tooth-brushing, parental supervision, use of a baby toothbrush, and fluoridated dentifrice significantly decreased caries prevalence.

Conclusion: ECC is a serious public health problem in this population and measures to increase awareness should be undertaken. The target candidates for oral health promotion programs should include mothers, general dentists, pediatricians, nurses, primary care health workers, care-takers at day-care centers and gynecologists. (Eur J Dent 2012;6:141-152)

Key words: Early childhood caries; preschool; feeding habits; oral hygiene; prevalence; socioeconomic status

- 1 Department of Pediatric Dentistry, Manubhai Patel Dental College and Hospital Baroda, Gujarat, INDIA

2 Department of Pediatric Dentistry, The Oxford Dental College, Hospital and research Center, Bangalore, Karnataka, INDIA

${ }^{3}$ Department of Orthodontics, Dental Health Department. Member, Dental Bio-materials Research Chair, College of Applied Medical Sciences, King Saud University, Riyadh, SAUDI ARABIA
4 Department of Pediatric Dentistry AECS Maruthi Dental College and Hospital Bangalore, Karnataka, INDIA

- Corresponding author: Dr. Prashanth Prakash Department of Pediatric Dentistry Manubhai Patel Dental College and Hospital Baroda, Gujarat, INDIA

Tel: +919986281096

Fax: +91265336350

Email: drprashanth25agmail.com 


\section{INTRODUCTION}

Early childhood caries is a complex disease involving the maxillary primary incisors within a month after eruption and spreads rapidly to involve other primary teeth. ${ }^{1}$ It is a serious socio-behavioral and dental problem that afflicts infants and toddlers worldwide. ${ }^{2}$ The definitions of ECC in the published literature vary, making comparisons among studies difficult. ${ }^{1,3}$ For example, some of the definitions have included 1 or more incisors with decay, ${ }^{4} 2$ or more incisors with decay, ${ }^{5}$ and even 3 or 4 maxillary incisors with decay. ${ }^{6}$ Therefore, in 2003, the American Academy of Pediatric Dentistry (AAPD) defined ECC as the presence of one or more decayed (noncavitated or cavitated), missing (due to caries), or filled tooth surfaces in any primary tooth in a child up to 71 months of age or younger. The academy also specifies that, in children younger than 3 years of age, any sign of smooth surface caries is indicative of severe early childhood caries (S-ECC). From ages 3 through 5, 1 or more cavitated, missing (due to caries) or filled smooth surfaces in primary maxillary anterior teeth or decayed, missing, or filled score of $\geqslant 4$ (age 3 ), or $\geqslant 5$ (age 4 ), or $\geqslant 6$ (age 5) surfaces constitutes S-ECC.

ECC is a multi-factorial disease. ${ }^{2}$ The factors include a susceptible host, fermentable carbohydrate diet, presence of dental plaque, high number of cariogenic micro-organisms such as mutans streptococci, lactobacillus and time. ${ }^{8}$ It is also thought that there may be unique risk factors for caries in infants and young children. ECC has been associated with demographic characteristics, oral hygiene practices, parental attitudes, educational status of mother, socio-economic status, temperament of the child, mouth breathing habit, siblings, pacifiers dipped in honey, children with chronic illness or special health care needs and other feeding habits, maternal nutrition, psychosocial issues, frequent use of medications and parenting practice. ${ }^{9-15}$ Even ethnicity has been identified as a factor, as the prevalence of tooth decay in children remains high among ethnic minorities and various North American aboriginal population. ${ }^{16,17}$

ECC is a serious public health problem in very young children, and although it is not life threatening, if left untreated it may lead to pain, bacteremia, compromised chewing ability, and toxic overdose of analgesics (acetaminophen) administered during the early stages, followed by malocclusion in permanent dentition, phonetic problems, suboptimal health, lower self-esteem, and failure to thrive. .8,19 $^{10}$ Also, it has been demonstrated that dental caries can gradually reduce a child's ability to gain weight, which may get reversed after complete oral rehabilitation. ${ }^{20}$

ECC has also been described as a social, political, behavioral, medical, psychological, economical and dental problem. ${ }^{21}$ It is considered as a social and political problem because it is endemic in disadvantaged children, regardless of race, ethnicity, or culture. These disadvantaged children suffer from diseases; hunger, lack of education, family support, and parental employment. ${ }^{22}$ ECC can be a medical problem, because infants with ECC continue to grow at a slower pace compared to caries-free infants. ${ }^{23}$ Children born after maternal complications during pregnancy or who have had traumatic births are at risk of developing ECC. ${ }^{24}$ Moreover, children with severe ECC often require costly treatment with hospitalization under sedation or general anesthesia. ${ }^{25}$ Preventive methods are not applied to many vulnerable children, who later develop serious dental problems.

The prevalence of ECC is estimated to range from $1 \%$ to $12 \%$ in preschoolers of developed countries ${ }^{26}$ and from $50 \%$ to $80 \%$ in high-risk groups, ${ }^{15,17,21,24}$ including immigrants and aboriginal Canadians. The prevalence of ECC and its association with feeding habits and oral hygiene practices in preschool children of Kerala state which is a neighboring state of Karnataka in southern India, was evaluated by Jose and King. The results showed caries prevalence of $44 \%$ and the $\mathrm{dmft}$ was 1.84. Severe-ECC was seen in $12 \%$ of the sample studied. They also concluded that the preschool children in Kerala, who were at high risk from developing caries lesions were those children with poor oral hygiene, who consumed snacks, who were given snacks as reward, and those who belonged to lower socio-economic status. ${ }^{2}$ However, because most studies on ECC have been conducted among specific ethnic, immigrant, and lower socio-economic communities, extrapolation of current risk assessment models to the general population is problematic. ${ }^{21}$

Bangalore, being a metropolitan city within Karnataka state, has inhabitants from different socioeconomic and cultural backgrounds. The city has leveraged its prowess in the information technology 
(IT) industry to emerge as the leading IT-BPO (Information Technology-Business Process Outsourcing) destination in India. Despite the seriousness of problems due to ECC, there has been a paucity of prevalence studies in Bangalore, which may be due to the difficulty of access to this age group. The most tragic fact about ECC may be that measures, which could render the condition entirely preventable, have not been implemented due to the multifactorial origin of this disease. Hence, knowledge on prevalence and associated factors of ECC is necessary to develop targeted interventions for prevention of subsequent tooth decay, and to decrease the number of children that require emergency treatment. So, the aim of this study was as follows:

1. To determine the prevalence of ECC in children aged between 8 and 48 months in urban Bangalore, India.

2. To determine possible associations of ECC with factors such as chronological age, birth weight, socio-economic status, educational status of the mother, feeding habits, and oral hygiene practices.

\section{MATERIALS AND METHODS}

This cross-sectional survey was conducted in Bangalore city, which is the capital of Karnataka state in India. With an estimated population of 5.8 million in 2001, Bangalore is the $3^{\text {rd }}$ most populous city in India and the 28th most populous city in the world. All inhabitants of the city use the local tap which has a low-fluoride level of $0.7 \mathrm{ppm}$ for domestic purposes.

This survey consisted of a random sample of 1500 children, both male and female aged between 8 and 48 months, attending playschools and private hospitals in different parts of urban Bangalore city, Karnataka. In the present study, private hospitals were selected for the collection of data for children less than 2 years, and play homes and day care centers were selected for older children. The age group selected for this study was 8 - 48 months because by 8 months of age at least 2 central incisors erupt and it has also been established that mutans streptococci can be found in the mouth from as early as 6 months of age, even prior to tooth eruption. ${ }^{27} \mathrm{All}$ children were included in the study after obtaining informed consent from the mother. Not all individual data sets were complete and those with missing data sets were excluded from the modeling step.

An informed consent was obtained from the mothers before each child was enrolled. Ethical clearance to conduct the study was obtained from the institutional review board.

A pilot survey was conducted among 20 children, in order to pre-test the method of examination, data collection forms, and to train and familiarize the examiner with the survey. The preliminary investigation was conducted in the research institute among the group of children of the same age, which was considered as an analogous population. Only 3 of the 20 children examined presented dental caries. Full agreement was reached on this result between the study examiner (PP) and two experienced Professor (SS, PS) in the Department of Pediatric Dentistry.

Clinical examination was performed by a sole examiner (PP) using disposable mouth mirrors for indirect vision of lingual areas of the teeth, and torch light. Mouth mirrors were used for indirect vision of lingual areas of the teeth. The community periodontal index (CPI) probe was used to confirm visual evidence of caries on the occlusal, buccal and lingual surfaces. During the examination, the older children were seated on a chair and infant were examined with assistance of their mothers', by means of the "knee-to-knee" technique. Gauze pads were used to clean and dry teeth surfaces before examination. A prior schedule for data collection was prepared and an average of $40-50$ children was examined per day. A dental surgeon was sitting close to the examiner so that the codes could be easily heard and recorded correctly. Radiographs were not taken due to practical reasons. The WHO criteria (1997) for carious lesions were used to diagnose caries. ${ }^{28}$

\section{Questionnaire}

The mothers of children attending play schools and nursing homes were informed of the nature of the investigation directly or through the teachers. Participation involved dental examination of the child followed by a comprehensive interview with mothers. They completed a dental health questionnaire which included a series of questions regarding the child's chronological age, birth weight, socio-economic status, educational status of mother, feeding habits and oral hygiene practices.

Statistical Analysis

The clinical and questionnaire data were ana- 
lyzed using the statistical package for social sciences, Raleigh, North Carolina, USA (SPSS) version 12. The percentage of caries-affected and caries-free children within each variable category was compared using cross-tabulation procedure and the relative proportions within each group were analyzed using the chi-square test of association. In the above tests, "P" value of $<.05$ was considered as statistically significant.

\section{RESULTS}

The overall caries prevalence of 1500 children of urban Bangalore whose ages ranged from 8-48-months was $27.5 \%$ ( $n=413$ ) with a mean deft of 0.854 . The caries prevalence in different age groups showed an increase with age (Table 1). In the present study, the number of children affected with ECC in relation to birth weight of children (Table 2), socio-economic status (Table 3), and mother's education level (Table 4) was evaluated. Low birth weight as defined by the WHO is weight at birth of less than $2.5 \mathrm{~kg}(5.5 \mathrm{lb}) .{ }^{74}$ Of the 1500 children studied, 499 (33.2\%) children had low birth weight $1<2.5$ $\mathrm{kgs})$, and $27 \%$ of these children were affected with ECC. The socio-economic status was based on the parent's annual income. The children were divided into 4 groups on the basis of income. Children with family annual income of less than Rs 50,000 (US \$ 1000) were included in group 1 and group 4 included children from higher family annual income of more than Rs 200,000 (US \$ 4000). The occurrence of ECC was found to be higher in children of low socio-economic status and uneducated mothers (Table 3, 4).

The effect of different feeding habits such as manner of feeding, on-demand breast feeding, bottle feeding at night, nutritional supplements given, in-between meal snacking, and use of pacifiers in the occurrence of ECC were analyzed (Table 5). The 1500 children included in this study cleaned their teeth on their own or were assisted by parents. The methods of cleaning, frequency of cleaning, cleaning aids used, dentifrice used and initiation of tooth brushing were analyzed as shown in Table 6.

\section{DISCUSSION}

The oral health of preschoolers is an overlooked aspect of childhood health and well-being, especially in cases of ECC. These children constitute a population vulnerable to caries because of their dependence and inability to communicate with their parents. In Southern India, dental caries prevalence in children below 6 years of age was comparatively low as reported by Gupta et al in relation to other parts of the country. The mean deft found in Karnataka (Bangalore), Andhra Pradesh and Kerala were $0.6,1.63$, and 2.1 respectively. ${ }^{30}$ Another study was conducted to compare the prevalence and pattern of caries in 4-51/2-year-old children of urban Bangalore and non-urban Chickaballapur within Karnataka state, India. The results showed caries prevalence of $66.3 \%$ with a mean deft of 2.9 in Bangalore city whereas in Chickballapur, the prevalence was $58.4 \%$ and the mean deft was $2.3 .{ }^{31}$ In the present study, the prevalence of ECC in urban Bangalore within Karnataka state was $27.5 \%$ with a mean deft of 0.854 . This shows a decreased trend of caries prevalence in urban Bangalore from 1987 to 2005. This level is higher than formerly reported in several European countries, but lower than the levels among several native North-American communities. ${ }^{32,33,34}$ The low prevalence observed in this study could be due to the increased use of fluoridated toothpastes available in the market, increased oral hygiene awareness as there are many oral health education programs organized by well-established dental institutions of Bangalore. Another possible reason could be to the rapid growth and development of Bangalore city not only area with respect to the area but also in terms of employment opportunities and education status. This could lead to increased awareness among the general public especially mothers, primary care health providers and secondary caretakers towards the dental health of their children.

\section{Age (Table 1)}

Determining the prevalence of caries in preschool children is a difficult process as the children of this age group are not easily accessible, uncooperative, a detailed examination of the oral cavity cannot be easily accomplished and no separate criteria has been developed for evaluating the extent and degree of caries in children below 3 years because of varied number of erupted teeth. ${ }^{35}$

Similar to the results of the previous studies, our present study also showed that caries preva-

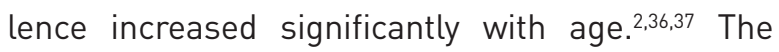
children of group 7 (44-48 months) demonstrated higher caries prevalence (37.2\%) than the younger age groups. The finding that caries experience and 
the number of confirmed cases of ECC increased with increasing age was as expected, because there is an increasing number of erupted primary teeth which become exposed to the oral environment and cariogenic challenge. Also, as children grow older there is a change in the dietary habits and hygiene practices. ${ }^{21}$

\section{Low Birth Weight (Table 2)}

Low birth weight and preterm births, predisposes to high levels of streptococcal colonization, in addition to favoring the development of enamel hypoplasia and salivary disorders. ${ }^{38}$ In the present study, $27 \%$ of low birth weight children were affected with ECC, which was not statistically significant. This is in accordance with the findings of another study by Shulman. ${ }^{39}$ However, some other similar studies have found a significant association between low birth weight and ECC. ${ }^{40,41}$ The present study had a disproportionate sample size between low birth weight and normal birth weight children. Therefore, further research is required to empha- size the correlation between low birth weight and caries prevalence in preschool children. The issues to be explored include the link between developmental enamel defects and caries, and the role of birth complications in the development of caries.

\section{Socio-Economic Status (Table 3)}

Social class may affect caries risk in many ways. Low income affects the degree of education, health, values, life styles and access to health care information, thereby increasing susceptibility to caries. A statistically significant correlation was found between caries prevalence and low socio-economic status, measured in terms of the income. The present study showed that higher the income, lower the caries prevalence, which is in accordance with the observations of some previous studies. 2,21,42 Low socio-economic status may increase ECC risk in several ways. Individuals from lower economic strata experience financial, social and material disadvantages that compromise their ability to care for themselves, obtain professional oral health care

Table 1. Prevalence of early childhood caries in relation to age.

\begin{tabular}{|c|c|c|c|c|c|}
\hline & Age in months & $\begin{array}{c}\text { Caries Affected } \\
\qquad N(\%)\end{array}$ & $\begin{array}{c}\text { Caries Free } \\
\qquad \mathrm{N}\end{array}$ & Total & Inference \\
\hline Group 1 & 08 to 13 & $1(1.14 \%)$ & 87 & 88 & \\
\hline Group 2 & 14 to 19 & 18 (23.3\%) & 59 & 77 & $\chi^{2}=68.60$ \\
\hline Group 3 & 20 to 25 & $7(11 \%)$ & 57 & 64 & Chi-square test \\
\hline Group 4 & 26 to 31 & 39 (17.4\%) & 185 & 224 & \\
\hline Group 5 & 32 to 37 & $118(28.7 \%)$ & 292 & 410 & \\
\hline Group6 & 38 to 43 & $126(35 \%)$ & 232 & 358 & \\
\hline \multirow[t]{2}{*}{ Group 7} & 44 to 48 & $104(37.2 \%)$ & 175 & 279 & $P<.001$ \\
\hline & Total & $413(27.5 \%)$ & 1087 & 1500 & \\
\hline
\end{tabular}

Table 2. Proportion of children with early childhood caries according to birth weight of child.

\begin{tabular}{|c|c|c|c|c|c|}
\hline & $\begin{array}{c}\text { Birth weight } \\
\text { (Kgs) }\end{array}$ & $\begin{array}{c}\text { Caries Affected } \\
\qquad N(\%)\end{array}$ & $\begin{array}{c}\text { Caries Free } \\
\text { N }\end{array}$ & $\begin{array}{c}\text { Total } \\
\mathrm{N}\end{array}$ & Inference \\
\hline Group 1 & Low (<2.5) & $135(27.1 \%)$ & 364 & 499 & $\begin{array}{c}\chi^{2}=0.09 \\
\text { Chi-square test }\end{array}$ \\
\hline \multirow[t]{2}{*}{ Group 2} & $>2.5$ & $278(27.8 \%)$ & 723 & 1001 & $P=.7693$ \\
\hline & Total & $413(27.5 \%)$ & 1087 & 1500 & \\
\hline
\end{tabular}

Table 3. Proportion of children with early childhood caries according to annual family income.

\begin{tabular}{|c|c|c|c|c|c|}
\hline & $\begin{array}{l}\text { Income in Indian Rupees } \\
\text { (Rs) }\end{array}$ & $\begin{array}{l}\text { Caries Affected } \\
\qquad N(\%)\end{array}$ & $\begin{array}{l}\text { Caries Free } \\
\qquad \mathrm{N}\end{array}$ & $\begin{array}{l}\text { Total } \\
\mathrm{N}\end{array}$ & Inference \\
\hline Group 1 & $<50,000 \mathrm{Rs}$ & $214(34.6 \%)$ & 404 & 618 & \multirow{2}{*}{$\begin{array}{c}\chi^{2}=45.94 \\
\text { Chi-square test }\end{array}$} \\
\hline Group 2 & $50,000-1$ lakh Rs & $74(24.2 \%)$ & 232 & 306 & \\
\hline Group 3 & 1 lakh - 2 lakhs Rs & $54(35.1 \%)$ & 100 & 154 & \multirow{2}{*}{$P<.001$} \\
\hline Group 4 & $>2$ lakhs Rs & $71(16.8 \%)$ & 351 & 422 & \\
\hline
\end{tabular}


services and live in a healthy environment, all of which lead to reduced resistance to oral and other diseases. ${ }^{2}$ It has also been reported that children from low socioeconomic background have more fatalistic health beliefs, lower perceived need for and utilization of dental health care services and poor eating habits. ${ }^{21,43}$

Educational Status of the Mother (Table 4)

As mothers are the primary caregivers of a child, low maternal education is related to higher caries prevalence in their children. ${ }^{2,21,44}$ In the study sample of $1500,38 \%$ children whose mothers had no schooling were affected with caries. This was statistically significant when compared to those children whose mothers had received higher education. The results of this study are similar to other studies, which show a strong association between mother's education and presence of caries in their children. This may be attributed to the lack of information and education about the oral health care for children in uneducated mothers. 2,21,37,44 However, recent research has shown a lack of any association between ECC and education level of the mother..$^{45}$

\section{Feeding Habits (Table 5)}

The improper feeding patterns like bottle feeding beyond one year, prolonged or on-demand breast feeding and children put to bed with nursing bottle are responsible for an increase in the exposure of primary teeth to fermentable carbohydrates. This increase is likely to promote both an early colonization by oral mutans streptococci and an increase in the number of these microorganisms in the dental plaque and saliva, which increases the risk of developing caries. ${ }^{46}$ These bacteria are usually transmitted to the child by their mothers within the first 2 years of life which is known as the win- dow of infectivity period in preschool children. The earlier these microorganisms are transmitted, the more severe will be the ECC in primary dentition. ${ }^{18}$

In the current study, 30\% children were exclusively breast fed and $12.7 \%$ children exclusively bottle fed. The remaining $57.2 \%$ of the children were both breast and bottle fed. The caries prevalence was marginally higher in exclusively breastfed children. This is in accordance with a study conducted in Brazil by Dini et al which stated that children who were exclusively breast fed had slightly higher caries prevalence. ${ }^{47} \mathrm{~A}$ recent study in the United States has indicated that infant breastfeeding and its duration, whether exclusive feeding or not, is not associated with any increased risk for ECC or S-ECC. ${ }^{48}$ A systematic review of the relationship between breastfeeding and ECC has thereby suggested that a definitive conclusion cannot be drawn due to the inconsistent methodological approach in the research which makes it difficult to compare findings. ${ }^{49}$ This shows that the influence of infant feeding per se on ECC remains a complex and somewhat controversial issue. Therefore, exclusive breastfeeding should be encouraged up to the sixth month, and maintained at least up to the second year, with flexibility in schedules or shifts, and complemented appropriately with weaning food..$^{50}$

On-demand breast feeding was practiced by 554 mothers, of whom 164 (29.6\%) children had caries. Of the 755 children whose mothers' did not practice on-demand breast feeding 202 (26.71\%) children had caries. Thus, there was significantly high caries prevalence in children whose mothers practiced on-demand breast feeding. Ad libitum breastfeeding or breastfeeding for longer durations decreases plaque $\mathrm{pH}$, thereby increasing the risk of ECC. Therefore mothers should be informed of how they

Table 4. Proportion of children with early childhood caries according to educational status of mother.

\begin{tabular}{|c|c|c|c|c|c|}
\hline & $\begin{array}{c}\text { Education Status of } \\
\text { Mother }\end{array}$ & $\begin{array}{l}\text { Caries Affected } \\
\qquad N(\%)\end{array}$ & $\begin{array}{c}\text { Caries Free } \\
\qquad \mathrm{N}\end{array}$ & Total & Inference \\
\hline Group 1 & No Schooling & $142(37.9 \%)$ & 232 & 374 & \\
\hline Group 2 & Primary School & $43(33.8 \%)$ & 84 & 127 & \\
\hline Group 3 & $\begin{array}{l}\text { Higher Secondary } \\
\text { School }\end{array}$ & $109(29.1 \%)$ & 374 & 483 & $\chi^{2}=35.20$ \\
\hline Group 4 & $\begin{array}{l}\text { Pre-university Col- } \\
\text { lege }\end{array}$ & $17 \quad(28.8 \%)$ & 42 & 59 & Chi-square test \\
\hline Group 5 & Graduate & $94 \quad(22.3 \%)$ & 327 & 421 & \\
\hline \multirow[t]{2}{*}{ Group 6} & Post Graduate & $8 \quad(22.2 \%)$ & 28 & 36 & $P<.05$ \\
\hline & Total & $(27.5 \%)$ & 1087 & 1500 & \\
\hline
\end{tabular}


can reduce the probability of ECC by discouraging breast-feeding on demand, transitioning to use of a regular cup at 12 months of age, and cleaning the child's mouth regularly once the first primary tooth has erupted as suggested by American Academy of Pediatric Dentistry guidelines. ${ }^{7}$

In the present study, of the 412 children who were bottle-fed at night, a significantly higher percentage (40.7\%) of children had caries in comparison with the other group. This conclusion agrees with other studies that examined bottle feeding in detail and reported that the duration of bottle-feeding, particularly at night, is the most important determinant for ECC development rather than bottle-feeding itself. ${ }^{50,51,52}$ The reasons for this include decreased salivary flow and swallow reflex during sleep which allows liquid carbohydrate to remain in the mouth and pool around the teeth. This decreased rate at which carbohydrates are cleared from the oral cavity is a determinant in caries initiation. The anterior placement of the tongue protects the mandibular anterior teeth from the decay causing carbohydrate solutions. ${ }^{53}$

In the present study, $76.8 \%$ children consumed snacks between meals. A statistically significant correlation was found between caries prevalence and consumption of in-between meal snacks. Children having in-between meal snacking habit had higher caries prevalence (29.2\%). The eating hab- its of the children have dramatically changed in the past few years. Milk consumption has decreased whereas the consumption of soft drinks, juices, non-citric beverages, and carbohydrates has increased. These habits have been correlated with a higher prevalence of ECC. ${ }^{54,55}$ The sugar intake in the early stages of life may accelerate the accumulation of mutans streptococci in the infant's mouth which is a risk factor for caries. The mutans streptococci colonization is directly proportional with increased snacking habits leading to increase in caries prevalence among preschool children. ${ }^{56}$ The present study supports the earlier studies which state that frequent consumption of foods, snacks and drinks in-between meals increases the risk for caries. ${ }^{21,36}$ Hence, nutritional recommendations of limiting the snacking time among children and encouraging regular meals is essential.

Nutritional supplements and dietary factors have a profound and lasting effect on developing and developed dentition. It has also been suggested that pre-natal and peri-natal malnutrition are often the causes of enamel hypoplasia, reduced salivary secretion and low buffering capacity. ${ }^{57,58}$ In addition, poor oral hygiene, insufficient exposure to fluoride, and general psychosocial stress is common in underprivileged children. These variables may impede the natural resistances to the disease cycle of bacterial invasion, demineralization and dental car-

Table 5. Proportion of children with early childhood caries according to feeding habits.

\begin{tabular}{|c|c|c|c|c|c|c|}
\hline & & Caries Affected & Caries Free & Total & \multicolumn{2}{|c|}{ Inference } \\
\hline & & $N(\%)$ & $\mathrm{N}$ & $\mathrm{N}$ & $\begin{array}{c}\chi^{2} \\
\text { Chi-square test }\end{array}$ & $P$ \\
\hline \multirow{3}{*}{ Manner Of Feeding } & 1. Breast & $133(29.6 \%)$ & 317 & 450 & \multirow{3}{*}{1,81} & \multirow{3}{*}{0,403} \\
\hline & 2. Bottle & $47(24.6 \%)$ & 144 & 191 & & \\
\hline & 3. Both & $233(27.1 \%)$ & 626 & 859 & & \\
\hline \multirow{2}{*}{ On-demand Breast Feeding } & Yes & $164(29.6 \%)$ & 307 & 554 & \multirow{2}{*}{17,71} & \multirow{2}{*}{0,001} \\
\hline & No & $202(26.7 \%)$ & 636 & 755 & & \\
\hline \multirow{2}{*}{ Bottle Feeding At Night } & Yes & $168(40.7 \%)$ & 244 & 412 & \multirow{2}{*}{160,74} & \multirow{2}{*}{0,001} \\
\hline & No & $52(3.1 \%)$ & 586 & 638 & & \\
\hline \multirow{2}{*}{ Between-meal Snacks } & Yes & $337(29.2 \%)$ & 815 & 1152 & \multirow{2}{*}{7,36} & \multirow{2}{*}{0,007} \\
\hline & No & $76(21.8 \%)$ & 272 & 348 & & \\
\hline \multirow{2}{*}{ Nutritional Supplements } & Supplements & $6 /(27 \%)$ & 472 & 539 & \multirow{2}{*}{96,11} & \multirow{2}{*}{0,001} \\
\hline & No supplements & $346(36 \%)$ & 615 & 961 & & \\
\hline \multirow{2}{*}{ Pacifier Use } & Yes & $48(26.1 \%)$ & 136 & 184 & \multirow{2}{*}{0,22} & \multirow{2}{*}{0,6392} \\
\hline & No & $365(26.8 \%)$ & 951 & 1316 & & \\
\hline \multirow{3}{*}{ Pacifier dipped in } & Honey or sugar & $22(28.9 \%)$ & 54 & 76 & \multirow{3}{*}{0,358} & \multirow{3}{*}{0,492} \\
\hline & Not dipped & $26(24 \%)$ & 82 & 108 & & \\
\hline & Total & 48 & 136 & 184 & & \\
\hline
\end{tabular}


ies. ${ }^{1}$ It has been shown previously that nutritional supplementation is one of the effective strategies for the prevention and control of dental caries. ${ }^{58,59}$ In the present study, nutritional supplementation included vitamins, iron, calcium and fluorides. Those children who consumed these supplements had significantly lower caries experience. The results of this study also suggest that, while evaluating prolonged nursing habits with bottle or breast-feeding as a contributory factor of ECC, other factors such as intake of cariogenic food and oral hygiene habits should also be considered.

A study has shown that dipping a pacifier in sugar is associated with early colonization of mutans streptococci in pre-dentate infants, but a systematic review conducted by Perssini did not show any consistent correlation between the use of pacifiers and the development of ECC regardless of dipping the pacifier in sugar or not dipping. 27,60 The present study also did not show any significant relation between the use of pacifiers and ECC.

\section{Oral Hygiene Habits (Table 6)}

Many authors have shown that regular tooth brushing may counteract the effects of a cariogenic diet. ${ }^{15,33,61,62,63}$ Therefore, variables such as tooth brushing under supervision, frequency of brush- ing, type of dentifrice, and tooth cleaning aids were analyzed in this study.

Previous studies and experience have shown that preschool children do not understand or have the manual dexterity to maintain good oral hygiene. ${ }^{64,36}$ Hence, parental assistance and guidance is essential to reduce the risk of developing caries. Tooth brushing by parents or caregivers has the potential of removing dental plaque more effectively, optimally saturating the oral environment with fluoride, thereby decreasing the risk of caries among their children. ${ }^{47}$ In the present study, prevalence of caries in those children who practiced tooth brushing by themselves was significantly higher than in those children who brushed under parental supervision. The result of this study is in accordance with another recent study which showed that children brushing without assistance by the mother were at high risk of developing ECC..$^{36}$ In contrast, it has been observed in another similar study that adult supervision of children's tooth brushing was not associated with ECC. ${ }^{21}$ However, the importance of prolonged participation of parents in tooth cleaning of these preschool children should be emphasized.

Most children in the present study brushed or cleaned their teeth once a day. When compared to

Table 6. Proportion of children with early childhood caries in relation to oral hygiene habits.

\begin{tabular}{|c|c|c|c|c|c|c|}
\hline \multirow[t]{2}{*}{$\mathrm{N}(\%)$} & & \multirow{2}{*}{$\begin{array}{c}\text { Caries } \\
\text { Affected } \\
\text { N }\end{array}$} & \multirow{2}{*}{$\begin{array}{c}\text { Caries Free } \\
\text { N }\end{array}$} & \multirow{2}{*}{$\begin{array}{c}\text { Total } \\
\chi^{2} \\
\text { Chi-square test }\end{array}$} & \multicolumn{2}{|c|}{ Inference } \\
\hline & & & & & $\mathrm{p}$ & \\
\hline \multirow{3}{*}{ Tooth Cleaning } & Child cleaning & $110(38.6 \%)$ & 175 & 285 & \multirow{3}{*}{35,18} & \multirow{3}{*}{0,001} \\
\hline & Mother cleaning & $127(31.7 \%)$ & 274 & 401 & & \\
\hline & Child cleaning under supervision & $176(21.6 \%)$ & 638 & 814 & & \\
\hline \multirow{3}{*}{ Frequency Of Cleaning } & Once & $364(34.7 \%)$ & 686 & 1050 & \multirow{3}{*}{87,68} & \multirow{3}{*}{0,001} \\
\hline & Twice & $48(10.9 \%)$ & 394 & 442 & & \\
\hline & > Twice & $1(12.5 \%)$ & 7 & 8 & & \\
\hline \multirow{2}{*}{ Tooth Cleaning At Night } & Yes & $91(26.7 \%)$ & 250 & 341 & \multirow{2}{*}{0,16} & \multirow{2}{*}{0,6904} \\
\hline & No & $322(27.8 \%)$ & 837 & 1159 & & \\
\hline \multirow{2}{*}{ Dentifrice Used } & Fluoridated & $69(18.3 \%)$ & 309 & 378 & \multirow{2}{*}{25,48} & \multirow{2}{*}{0,001} \\
\hline & Non-Fluoridated & $344(31.9 \%)$ & 736 & 1080 & & \\
\hline \multirow{4}{*}{ Initiation Of Tooth Cleaning } & 6 to 12 & $196(30.1 \%)$ & 456 & 652 & \multirow{4}{*}{0,61} & \multirow{4}{*}{0,893} \\
\hline & 13 to 18 & $168(30.9 \%)$ & 376 & 544 & & \\
\hline & 19 to 24 & $67(32.7 \%)$ & 138 & 205 & & \\
\hline & $>24$ & $32(32.3 \%)$ & 67 & 99 & & \\
\hline \multirow{3}{*}{ Method of Cleaning } & Baby Brush & $381(28.3 \%)$ & 961 & 1342 & \multirow{3}{*}{16,45} & \multirow{3}{*}{0,001} \\
\hline & Finger & $32 \quad(27.6 \%)$ & 84 & 116 & & \\
\hline & Soft Cloth & 0 & 42 & 42 & & \\
\hline
\end{tabular}


those children who brushed or cleaned their teeth more than once a day, these children had significantly higher caries prevalence. This suggests that tooth brushing with a frequency of at least twice a day under parental guidance using a fluoridated toothpaste may spare the teeth from developing caries by removing dental plaque more effectively, there by optimally saturating the oral environment with fluoride, and decreasing the risk of caries among their children. ${ }^{65}$ Parental assistance and daily frequency of tooth brushing have been shown to be major determinants of declining ECC experience in European countries. ${ }^{61,66}$

Fluoride is presently the corner stone of dentifrice anti-caries therapy. Tooth-brushing with fluoridated dentifrice has played a major role in the decline of caries worldwide. ${ }^{65}$ The results of the present study also showed that those children who used fluoridated dentifrice had significantly lower caries prevalence. The impact of the use of fluoridated dentifrice and the total fluoride intake in preschool children is a controversial issue. A concentration of $1450 \mathrm{ppm}$ fluoride in toothpastes was shown to reduce caries in children but this increased the chances of fluorosis. ${ }^{67,68}$ The concentration of fluoride in toothpastes was not assessed as it varies from country to country depending on the government regulations. In India, most of the commercially available toothpastes are either nonfluoridated Ayurvedic toothpaste (Anchor, Meswa) or fluoridated (Colgate, Pepsodent) with a fluoride content of more than 1000ppm. Most of the parents were not familiar with the difference in toothpaste content and many did not know the effect of fluoride content in toothpastes on their child's teeth. In most cases, the parents used the same toothpaste, which they were using, for their children with perhaps lesser amount of paste. This may be due to lack of awareness among parents about the benefits and risks associated with use of fluoridated toothpastes in preschool children. Therefore, it is time that parents are instructed to delay the use of fluoridated dentifrice until the child is older than 24 months and use non-fluoridated toothpaste in these young children. In older children above 2 years, a pea-sized amount of fluoridated toothpaste should be used. Instructions should be given to the parents so that they make sure their children rinse and expectorate thoroughly after tooth brushing to avoid excessive ingestion of fluoride from toothpaste. .9,70 $^{-70}$
At present tooth-brushing and other mechanical cleaning procedures are considered to be the most reliable means of maintaining oral hygiene. Brushes are more effective in cleaning proximal, marginal and occlusal areas of the teeth. The soft brush is preferable for most uses in young children because of the likelihood of gingival tissue trauma and increased inter-proximal cleaning ability. ${ }^{63}$ The present study showed that $1132(89.4 \%)$ of the children used baby brush to clean their teeth. These children had significantly lower caries prevalence, when compared to those children who cleaned their teeth using their finger. In a similar study, it was found that $60 \%$ of the children who used tooth brush to clean their teeth were free of caries. ${ }^{2}$ Therefore, dental health behaviors such as use of fluoridated dentifrice with baby toothbrush significantly reduced ECC experience, possibly reflecting desirable parental dental knowledge and education. However, these preferred parental behaviors may be subject to a recall and response bias.

Some of the limitations in the present study were deriving detailed and accurate information from the parents regarding the feeding practices, contents of the feeding bottle, composition of snacks consumed and weaning. Also, the information obtained from mothers regarding child rearing practices may not be totally reliable. Further data collection is necessary for these factors to be put under statistical evaluation.

Data obtained may serve as a base line for planning and evaluation of community development and oral health promotion programs. Although future community initiatives have the potential to increase community knowledge of ECC, the ultimate challenge will be sustaining long term behavioral change among parents. The burden of dental decay in this population reveals the need for effective preventive methods. Thus, both medical providers and those working with pregnant women and the very young must play an integral role in the prevention and early detection of ECC. It is important for pediatricians, family physicians and other health service providers encountering expectant mothers and very young children to be cognizant of ECC and its ramifications, as they represent the first line of defense. Ultimately community-based solutions should be explored and can be strengthened if used in conjunction with the existing and emerging strategies for promoting early childhood oral health and 
preventing dental decay. These strategies should include suppression of maternal reservoirs of mutans streptococci, health education of mothers to prevent vertical transmission of mutans streptococci, promoting the first dental visit by 12 months, providing anticipatory guidance, motivational interviewing (MI), using chemotherapeutics (e.g., fluoride varnish, silver diamine fluoride, povidone iodine[butadiene], chlorhexidine), water fluoridation, promote use of fluoridated dentifrice, dietary counseling, self-examination for early signs of ECC, and other previously tested methods which are potentially simple, cheap, effective, and appropriately practical for this community. 7,18,21,71 Although future community initiatives have the potential to increase community knowledge of ECC, the ultimate challenge will be sustaining long-term behavioral change among parents, caregivers and the community at large leading to appropriate parenting practices. The reason for increased ECC risk could be cultural differences in child rearing, infant feeding practices, and oral health beliefs. This survey has identified certain risk factors for the presence of ECC in preschool children within an Indian city. General dentists can use this information to target 1-5-year-old children and use the above preventive methods. Public funded oral health programs need to target children from lower socio-economic status and develop effective strategies to promote breast feeding and discourage inappropriate bottle feeding. ${ }^{21}$

$\mathrm{Ml}$ of mothers is a recent approach which is shown to have a greater positive effect on preschool children's dental health than the traditional health education approach. This approach enhanced the preventive behavior of mothers of young children at high risk of developing caries. ${ }^{71}$ Another important aspect of ECC which has not been explored is the role of care-takers of children attending day-care centers in cities. Recently, Mani et al have suggested that the care-takers of children attending day-care centers have an important role in promoting oral health among preschool children. ${ }^{72}$ During the recent years, there has been an increase in the number of working mothers in metropolitan cities; therefore most of the children spend a considerable amount of time in day-care centers. These parents have very limited control over their child's activities in such day-care centers. This indicates that further studies on ECC should focus more attention on family dynamics, environmental factors, behavior and society in which the children grow up.

\section{CONCLUSION}

Overall, the findings of this survey will form part of a baseline for the oral health assessment for children below 6 years of age in urban Bangalore city, India. From the results of this study, it can be concluded that caries prevalence in preschool children of urban Bangalore was 27.5\% with a mean deft of 0.854 and the risk factors for ECC included age, low maternal education, low socio-economic status, improper feeding and oral hygiene habits. There is evidence that suggests children with this condition remain at a high risk for future caries attack. The early identification of poor oral hygiene and improper feeding habits should be considered in preventive health promotion strategies in low socio-economic communities of Bangalore city, India.

\section{REFERENCES}

1. Davies GN. Early Childhood Caries - a synopsis. Community Dent Oral Epidemiol 1998;26:106-116.

2. Jose B, King NM. Early Childhood caries lesions in preschool children in Kerala,India. Pediatr Dent 2003;25:594600.

3. Ismail Al, Sohn W. A systematic review of clinical diagnostic criteria of Early Childhood Caries. J Public Health Dent 1999;59:171-191.

4. Huntington NL, Kim IJ, Hughes CV. Caries-risk factors for Hispanic children affected by early childhood caries. Pediatr Dent 2002;24:536-542.

5. Matee M, van't Hof M, Maselle S, Mikx F, van Palenstein HW. Nursing caries, linear hypoplasia, and nursing and weaning habits in Tanzanian infants. Community Dent Oral Epidemiol 1994;22:289-293.

6. Kelly M, Bruerd B. The prevalence of baby bottle tooth decay among two native American populations. J Public Health Dent 1987;47:94-97.

7. American Academy of Pediatric Dentistry Reference Manual 2002 - 03. Policies on Early Childhood Caries; Unique Challenges and Treatment Options. Pediatr Dent 2003;23:24- 25.

8. Ripa LW. Nursing caries: a comprehensive review. Pediatr Dent 1988;10:268-282.

9. Curson MEJ, Preston MEJ. Risk Groups: Nursing bottle caries/ caries in elderly. Caries Res 2004;38:24-27.

10. Quinonez R, Santos RG, Wilson S, Cross H. The relationship between child temperament and early childhood caries. $P e$ diatr Dent 2001;23:5-10. 
11. Filho NE, Mayer MPA, Pontes P, Pignatari ACC. Caries prevalence, levels of mutans streptococci, and gingival and plaque indices in 3.0 to 5.0-year- old mouth-breathing children. Caries Res 2004;38:572-575.

12. Perssini S. Pacifier use and early childhood caries. An evidence-based study of literature. J Can Dent Assoc 2003;69:16-22.

13. Tinanoff N, O'Sullivan DM. Early Childhood Caries: overview and recent findings. Pediatr Dent 1997;19:12-15.

14. Wyne AH. Early childhood caries: nomenclature and case definition. Community Dent Oral Epidemiol 1999;27:313-315.

15. Reisine S, Douglass JM. Psychosocial and behavioral issues in early childhood caries. Community Dent Oral Epidemiol 1998;26:32-44.

16. Albert RJ, Cantin RY, Cross HG, Castaldi CR. Nursing caries in the Inuit children of the Keewatin. J Can Dent Assoc 1988;54:751-758.

17. Shaw L, Clark DC, Edger NP. The oral health status of Cree children living in Chisasibi, Quebec. J Can Dent Assoc 1987;53:201-205.

18. Kagihara LE, Niederhauser VP, Stark M. Assessment, management and prevention of Early Childhood caries. $J \mathrm{Am}$ Acad Nurse Pract 2009;21:1-10.

19. Casamassimo PS, Thikkurissy S, Edelstein B, Maiorini E. Beyond the dmft: The human and Economic cost of Early childhood caries. J Am Dent Assoc 2009;140:650-657.

20. Acs G, Shulman R, Ng MW, Chussid S. The effect of dental rehabilitation on the body weight of children with early childhood caries. Pediatr Dent. 1999;21:109-113.

21. Hallett KB, O'Rourke PK. Social and behavioural determinants of early childhood caries. Aust Dent $J$ 2003;48:27-33.

22. O'Sullivan DM, Tinnanoff $N$. Social and biological factors contributing to caries of the maxillary anterior teeth. Pediatr Dent 1993;15:41-44.

23. Peretz B, Kafka I. Baby bottle tooth decay and complications during pregnancy and delivery. Pediatr Dent 1997;19:34-36.

24. Horowitz HS. Research issues in early childhood caries. Community Dent Oral Epidemiol 1998;26:67-81.

25. Kalnellis MJ, Damiano PC, Momary ET. Medication costs associated with the hospitalization of young children for restorative treatment under general anesthesia. $J$ Public Health Dent 2000;60:28-32.

26. Burt BA, Eklund SA. Dentistry, dental practice, and the community. 5th ed. Philadelphia: Saunders 1999:227-228.

27. Wan AKL, Seow WK, Purdie DM, Bird PS, Walsh LJ, Tudehope DI. Oral colonization of Streptococcus mutans in six-month-old predentate infants. J Dent Res 2001;80:20602065.

28. World Health Organization. Oral Health Surveys - basic methods. Geneva: WHO; 1997.
29. World Health Organization, Guidelines for mothers of low birth weight children, 2004.

30. Johnson NW. Dental Caries: Markers of high and low risk groups and individuals. Cambridge University Press, Cambridge, 1991.

31. Virjee K, Aradhya SMR. Caries pattern in urban and non-urban children 4--51/2 year old. J Indian Dent Assoc 1987;59:113116.

32. Silver DH. A comparison of 3-year-olds' caries experience in 1973, 1981 and 1989 in a Hertfordshire town, related to family behaviour and social class. Br Dent $J$ 1992;172:191197.

33. Wendt LK, Hallonsten AL, Koch G. Dental caries in one- and two-year-old children living in Sweden. Part I-A longitudinal study. Swed Dent J 1991;15:1-6.

34. Harrison RL, Davis DW. Caries experience of Native children of British Columbia, Canada, 1980-1988. Community Dent Oral Epidemiol 1993;21:102-107.

35. Damle SG. Epidemiology of Dental Caries in India. In: Pediatric Dentistry. Arya Publishing House, New Delhi 2002;7596.

36. Ibrahim S, Nishimura M, Matsumura S, Rodis OMM, Nishida A, Yamanaka K, Shimono T. A longitudinal study of early childhood caries risk, dental caries and lifestyle. Pediatric Dent J 2009;19:174-180.

37. Livny A, Assali R, Sgan-Cohen HD. Early child hood caries among a Bedouin community residing in eastern outskirts of Jerusalem. BMC Public Health 2007;7:167

38. Seow WK. Biological mechanisms of early childhood caries. Community Dent Oral Epidemiol 1998;26:8-27.

39. Shulman JD. Is there an association between low birth weight and caries in the primary dentition? Caries Res 2005;39:161-167.

40. Lai PY, Seow WK, Tudehope DI, Rogers Y. Enamel hypoplasia and dental caries in very-low birth weight children: a casecontrolled, longitudinal study. Pediatr Dent 1997;19:42-49.

41. Fearne JM, Bryan EM, Brook AH, Williams DM. Enamel defects in the primary dentition of children born weighing less than 2000gms. Br Dent $J$ 1990;168:433-437.

42. Rodrigues CS, Sheiham A. The relationships between dietary guidelines, sugar intake and caries in primary teeth in low income Brazilian 3-year-olds: a longitudinal study. Int J Paediatr Dent 2000;10:47-55.

43. Chen M. Oral health of disadvantaged populations. In: Cohen L, Gift H, eds. Disease prevention and Oral Health promotion. Copenhagen: Munksgaard, 1995.

44. Jin B, Ma D, Moon H, Paik D, Hahn S, Horowitz AM. Early Childhood Caries: Prevalence and risk factors in Seoul, Korea. J Pub Health Dent 2003;63:183-188. 
45. Schroth RJ, Moore P, Brothwell DJ. Prevalence of early child hood caries in four Mannitoba communities. $J$ Can Dent Assoc 2005:71;567.

46. Petti S, Cairella G, Tarsitani G. Rampant Early Childhood Dental Decay: an example from Italy. $J$ Pub Health Dent 2000;60:3

47. Dini EL, Holt RD, Bedi J. Caries and its association with infant feeding and oral health related behaviours in 3-4 years old Brazilian children. Community Dent Oral Epidemiol 2000;28:241-248.

48. lida $H$, Auinger $P$, Billings RJ, Weitzman M. Association between infant breastfeeding and early childhood caries in the United States. Pediatrics 2007;120:944-952.

49. Valaitis R, Hesch R, Passarelli C, Sheehan D, Sinton J. A systematic review of the relationship between breastfeeding and early childhood caries. Can J Public Health 2000;91:411417.

50. Weinstein P, William F.S, Fraser-Lee N, Shimono T, Tsubouchi J. Epidemiologic study of 19-month-old Edmonton, Alberta children. Caries rates and risk factors. ASDC J Dent Child 1998;52: 60.

51. Oulis BJ, Verdouses ED, Vadiakas G, Lygidakis AJ. Feeding practices of Greek children with and without nursing caries. Pediatr Dent 1999;21:409-416.

52. Febres C, Echeverri EA, Keene HJ. Parental awareness, habits, and social factors and their relationship to baby bottle tooth decay. Pediatr Dent 1997;19:22-27.

53. Schwartz SS, Glenn Rosivack R, Michelotti P. A child's sleeping habit as a cause of nursing caries. ASDC J Dent Child 1993;53:22-25

54. Nunn ME, Braunstein NS, Krall Kaye EA, Dietrich T, Garcia RI, Henshaw MM. Healthy Eating Index is a predictor of Early Childhood Caries. J Dent Res 2009;88:361- 366.

55. Dye BA, Shenkin JD, Ogden CL, Marshall TA, Levy SM, Kanellis MJ. The relationship between healthful eating practices and dental caries in children aged 2-5 years in the United States, 1988-1994. J Am Dent Assoc 2004;135:55-66.

56. Slavkin HC. Streptococcus mutans, early childhood caries and new opportunities. J Am Dent Assoc 1999;130:17871792.

57. Johansson I, Saeiinstrom AK, Rajan BP, Parameswaran A. Salivary flow and dental caries in Indian children suffering from chronic malnutrition. Caries Res 1992;26:38-43. 58. Marques APF, Messer LB. Nutrient intake and dental caries in the primary dentition. Pediatr Dent 1992;14:314-321.

58. Teotia SPS, Teotia M. Dental caries: a disorder of high fluoride and low dietary calcium interactions. Fluoride 1994;27:59-66.
59. Peressini S. Pacifier use and early childhood caries: an evidence-based study of the literature. J Can Dent Assoc 2003;69:16-19.

60. Schroder U, Granath L. Dietary habits and oral hygiene as predictors of caries in 3 -year-old children. Community Dent Oral Epidemiol 1983;11:308-311.

61. Tsai Ai, Johnsen DC, Lin YH, Hsu KH. A study of risk factors associated with nursing caries in Taiwanese children aged 24-48 months. Int J Pediatr Dent 2001;11:147-149.

62. Loe H. Oral hygiene in prevention of dental caries and periodontal diseases. Int Dent J 2000;50:129-139.

63. Dilley GJ, Dilley DH, Machen JB. Prolonged nursing habit: a profile of patients and their families. ASDC J Dent Child 1980; March:26-31.

64. King NM, Isabel IM, Wu Tsai JSJ. Caries prevalence and distribution and oral health habits of zero- to four old children in Macau, China. ASDC J Dent Child 2003;70:3-5.

65. Vanobbergen J, Martens L, Lesaffre E, Bogaerts K, Declerck $D$. Assessing risk indicators for dental caries in the primary dentition. Community Dent Oral Epidemiol 2001;29:424-434.

66. Davies GM, Worthington HV, Ellwood RP. A randomised controlled trial of the effectiveness of providing free fluoride toothpaste from the age of 12 months on reducing caries in 5-6 year old children. Community Dent Health 2002;19:131136.

67. Tavener JA, Davies GM, Davies RM, Ellwood RP. The prevalence and severity of fluorosis in children who received toothpastecontaining either 440 or 1,450 ppm $F$ from the age of 12 months in deprived and less deprived communities. Caries Res 2006;40:66-72.

68. Yasin-Hamekar S. Nursing Caries - A Review. Clinical Preventive Dentistry 1988;10:3-7.

69. Milgrom PM, Huebner CE, Ly KA. Fluoridated toothpaste and the prevention of early childhood caries: a failure to meet the needs of our young. J Am Dent Assoc 2009;140:628630.

70. Weinstein P, Harrison R, Benton T. Motivating mothers to prevent caries: Confirming the beneficial effect of counseling. J Am Dent Assoc 2006;137:789-793.

71. Mani SA, Aziz AA, John J, Ismail NM. Knowledge, attitude and practice of oral health promoting factors among caretakers of children attending day-care centers in Kubang Kerian, Malaysia: A Preliminary study. J Indian Soc Pedod Prevent Dent 2010;28:78-83. 